\title{
Remembrance OF PAST IMAGES OF TRICHINELLA
}

\author{
CAMPBELL W.C.*
}

\section{Summary :}

The development of achromatic microscopy and the invention of photography were contemporaneous with the earliest investigations on trichinellosis. The former was more important than the latter to $19^{\text {th }}$ century studies on Trichinella. A selection of images, diverse but not comprehensive, is presented to illustrate the early history of trichinellosis.

KEY WORDS : trichinellosis, history.

T The images here remembered are simply visual reminders of Trichinella and its investigators in times long gone. They are, in short, a tribute to our predecessors. To some of you these pictures will seem like old friends - perhaps old friends that you have not seen for years, and whose reappearance is therefore welcome. It is hoped that others of you will welcome these images as new acquaintances.

For the discovery of Trichinella, it was not necessary to have a compound microscope. Indeed, if Antonie Van Leeuwenhoek had focused one of his tiny single lenses on a flattened fragment of infected pork, the story of trichinellosis might have begun in the $17^{\text {th }}$ century. Nor was it necessary to have a color-corrected lens; but it happened that the spiral nematode larva was discovered at a time when compound microscopes with achromatic objectives were beginning to open up vast new opportunities in biomedical science. It also happened that the technique of light-sensitive chemical imagery was being developed at the same time. In all three cases, the worm, the achromatic lens and the photograph, there had been precursors and portents. But despite such embryonation, these technologies might be said to have hatched in the 1830s; to have reached the $2^{\text {nd }}$ developmental stage in the1840s; to have attained the effective $3^{\text {rd }}$ stage in mid-

Research Institute for Scientists Emeriti, Drew University, Madison, New Jersey, U.S.A.

Correspondence: W.C. Campbell.

Tel.: (973) 408-3096 - Fax: 973) 408-3504.

e-mail: wcampbel@drew.edu century; and to have reached early adulthood in the late $19^{\text {th }}$ century.

The joint exploitation of microscopy and photography was soon initiated, but did not soon become common. Photography was messy and cumbersome, even without trying to do it through a microscope, and it is hardly surprising that most images of Trichinella in the $19^{\text {th }}$ Century were drawings. Trichinologists, being bigger, were more easily photographed. What the drawings lacked in realism they made up for in beautiful craftsmanship and in instruction of the reader. Examples are shown here, but projection from slides does not fully capture the delicacy of the originals.

Two photographs of muscle-stage Trichinella by William Radam, an American medical huckster, were published by him in 1890, and illustrate both the strength and weakness of contemporary photomicrography (Fig. 1). Pr. Dupouy-Camet has kindly provided slides of another early photograph, originally intended for the presentation that was to have been given here by the late Pr. Jean Theodorides (Fig. 2). A stamped notation on the original photograph indicates that it had been in the possession of David Gruby, the famous French pioneer of microbiology. Unfortunately, it is not known when, where, or by whom the photograph was taken. Because Gruby died in 1898, we can say that the photograph dates from the $19^{\text {th }}$ Century, and that it illustrates a very high degree of technical mastery for that period.

Here, then, is a miscellany of images of the early history of trichinellosis, and a few unrelated pictures to establish its temporal correlation with the invention of photography.

Author's note: Most of the pictures shown at the conference have been published, and it is neither necessary nor feasible to reproduce them here. Radam's photographs of larval Trichinella, however, are reproduced here because they may not be readily found in the scientific literature. The photograph from Gruby's collection is included because it is not known to have been published. 

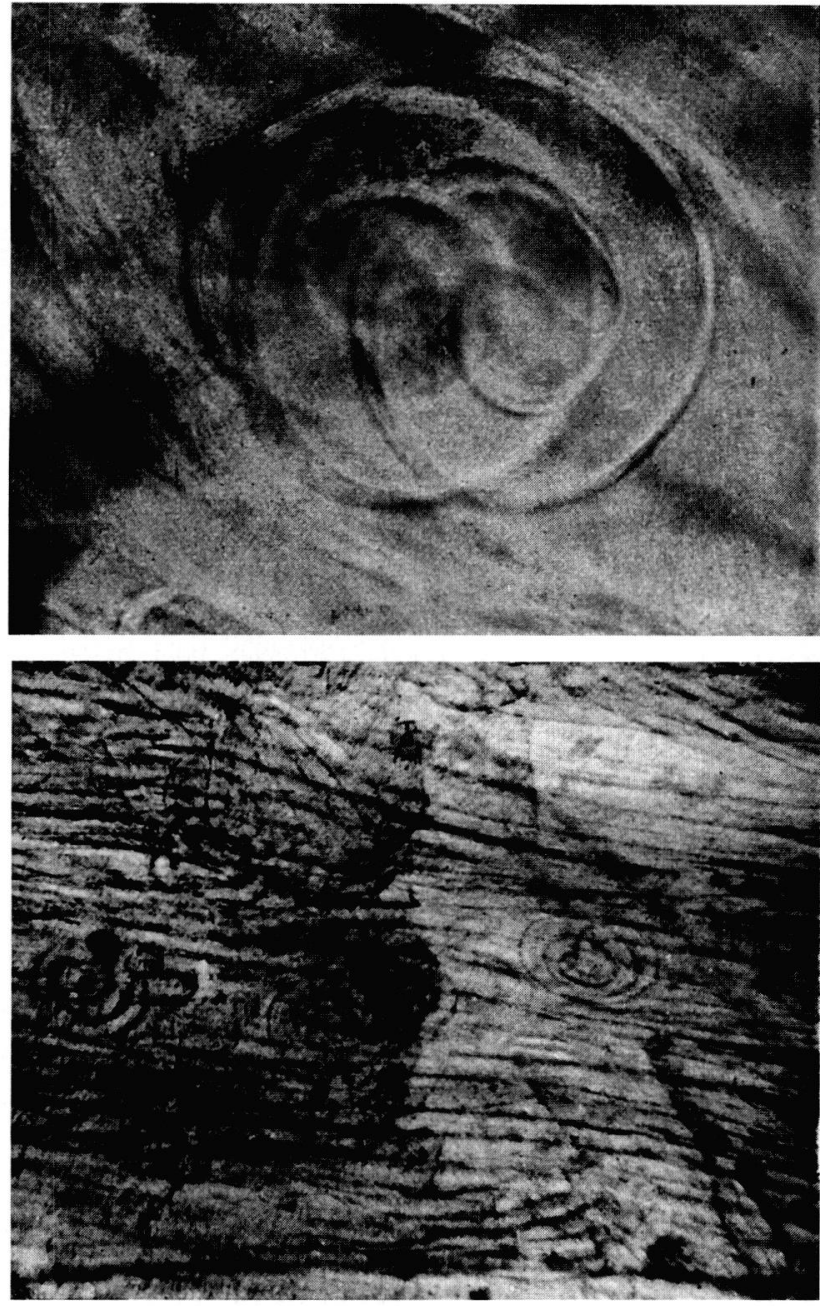

Fig. 1. - Plate with low- and high- magification photographs of Trichinella larvae, published by Radam in 1890 .

\section{ACKNOWLEDGEMENTS}

The photographs in Figure 1 are reproduced by courtesy of Dr. Allen Laskin, Drew University, from the copy of Radam's book in his possession. The photograph in Figure 2 is reproduced by courtesy of Pr. Jean Dupouy-Camet.

\section{REFERENCE}

RADAM W. Microbes and the Microbe Killer. Published by the author (Radam) and Knickerbocker Press, New York, 1890 .

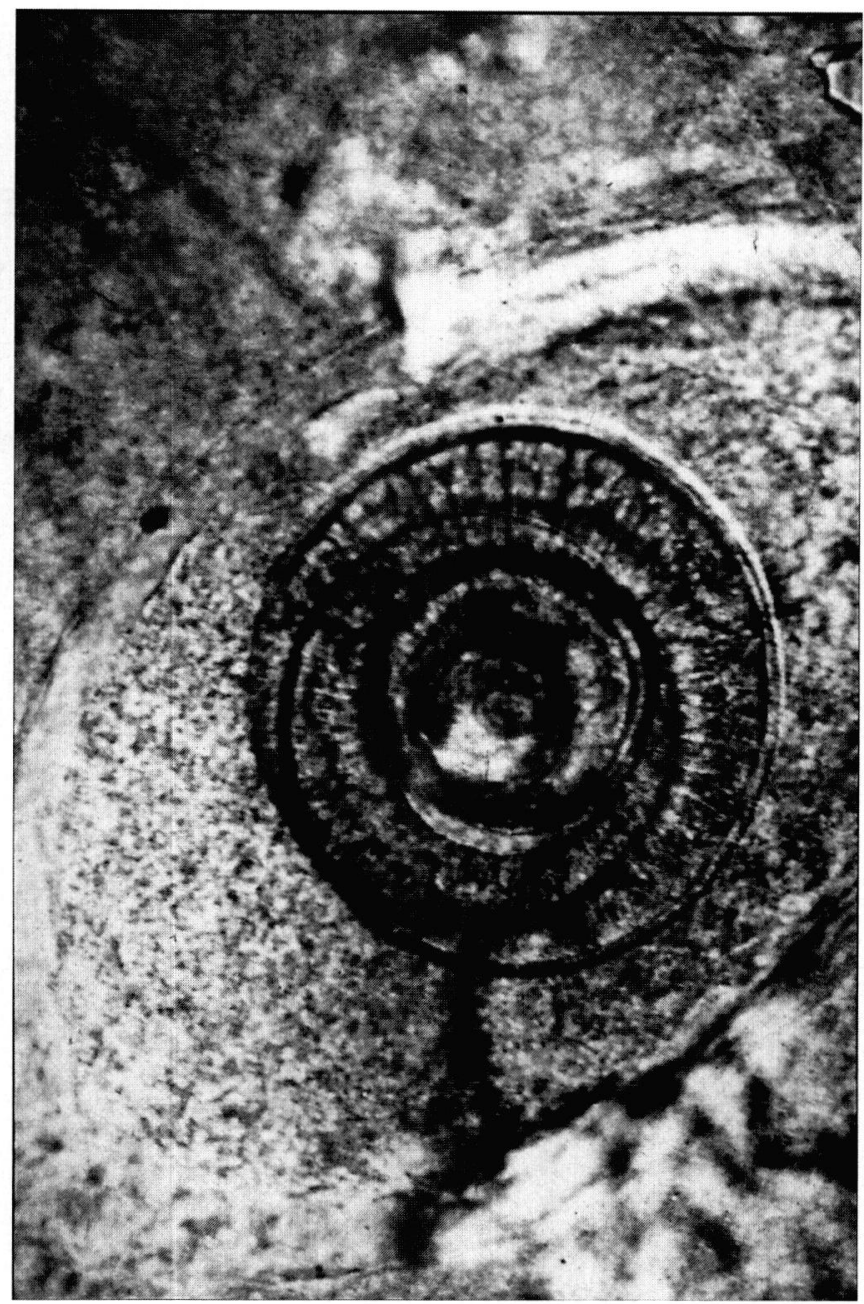

Fig. 2. - High-magnification photograph of a Trichinella larva (Gruby collection). Apparently taken in the $19^{\text {th }}$ Century, but not known to have been published. 